\title{
REVISIÓN DE LAS COMPLICACIONES NEUROLÓGICAS DEL EMBARAZO
}

Eduardo Palacios S. MD*

El embarazo, situación aceptada como normal, produce una serie de cambios en la mujer que conlleva a que varias entidades patológicas no solo neurológicas se manifiesten o se modifiquen. Es fácil suponer que si durante la gestación hay grandes cambios hormonales, lo más probable es que en ocasiones los acontecimientos anómalos les sean atribuidos.

En general la mujer cuando se embaraza tiene algún temor por la salud del futuro hijo, para nadie es extraño que muchas situaciones pueden llevar a malformaciones congénitas, por ejemplo las infecciones o aquellas de origen inmunológico, las enfermedades crónicas o degenerativas y en nuestro caso varias entidades neurológiças; y lo que es también grave y preocupa a muchas gestantes es lo relacionado con el empleo de medicamentos. ¿Hasta dónde puede llegar su toxicidad?

La mujer en edad fértil se pregunta entonces qué problemas puede traer el embarazo para ella o para su producto. El propósito principal de esta revisión es comentar de qué manera las entidades neurológicas más frecuentes pueden complicar el curso del embarazo, que patologías neurológicas solo se van a manifestar con la gestación y por último el problema que se le presenta al médico para recomendar algún medicamento dados los problemas teratogénicos bien conocidos de la mayoría de estos. ¿Cómo determinada patología neurológica influye en el embarazo o cómo el embarazo puede influir en esa patología?

\footnotetext{
* La revista Repertorio de Medicina y Cirugía recibe con beneplácito la serie Complicaciones Neurológicas del Embarazo, realizado por el Servicio de Neurología del Hospital de San José, que aparecerá en los números correspondientes a 2015 .

** Jefe del Servicio de Neurología, Hospital de San José. Miembro de la Sociedad de Cirugía de Bogotá. Profesor Titular, Fundación Universitaria de Ciencias de la Salud. Bogotá DC,Colombia.
}

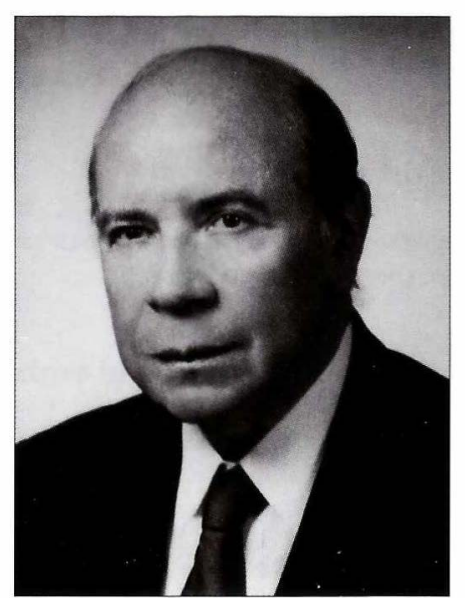

Dos de las entidades observadas a menudo en clínica neurológica, las migrañas y la epilepsia, sirven de ejemplo para comentar los efectos teratogénicos de los medicamentos. En estas la evolución de la enfermedad puede tener un curso impredecible, algunas mejoran, las crisis pueden disminuir e inclusive no presentarse mientras otras pueden empeorar. Más de la mitad de las pacientes con migraña dicen mejorar durante el embarazo; en el caso de la epilepsia algunas crisis pueden agravarse, por ejemplo las de origen focal se hacen más frecuentes. Lo ideal es no ingerir medicamentos durante la gestación, todos son teratogénicos en mayor o menor grado y el ácido valproico se considera el que más, porque puede producir malformaciones congénitas mayores y posibilidad de trastornos cognitivos en la infancia En las cefaleas el acetaminofén continúa considerándose el analgésico más seguro, pero hay otros que pueden emplearse según el periodo en que se encuentre la gestación. La esclerosis múltiple es una enfermedad frecuente en mujeres jóvenes, en edad fértil, por lo gene- 
ral angustia de manera importante a la paciente las consecuencias que pueda traerle el embarazo. ¿Va a complicar su enfermedad? ¿O bien la enfermedad y los medicamentos que debe recibir van a afectarla o a producir un recién nacido con defectos? Se ha visto que esta afección disminuye en el último trimestre del embarazo y se intensifica después del parto. De otra parte el empleo, hasta el momento, de medicamentos es un reto para el médico, la mayoría son teratogénicos y el único considerado categoría B sin complicaciones es el acetato de glatiramer, una macromolécula que parece que no pasa la barrera placentaria y tampoco tiene problemas con la lactancia. En las entidades mencionadas antes, en especial la esclerosis múltiple, es muy importante mantener informada a la paciente en cuanto a los riesgos, sobretodo de los medicamentos.

Es posible que en las patologías anotadas los cambios importantes desde el punto de vista hormonal e inmunológico sean los responsables de la modificación durante el embarazo. Por ejemplo hay aumento de algunas hormonas como los estrógenos, la progesterona, la prolactina y los glucocorticoides, y posterior al parto hay una disminución súbita e importante de estas que producen alteraciones en el proceso inflamatorio y en el sistema inmune.

Otras entidades que se observan durante la gestación y en las cuales los cambios hormonales no son los responsables directos de las neuropatías periféricas, tal es el caso del síndrome del túnel del carpo que se manifiesta en el tercer trimestre del embarazo, es muy probable que se deba al edema por retención de líquidos lo que puede comprometer esta región anatómica y lleva a la compresión del nervio mediano. Debido a la compresión de otro nervio, en este caso el femorocutáneo, encontramos la meralgia parestésica. También en el tercer trimestre aparece la parálisis facial periférica hasta tres veces más frecuente que en las no embarazadas. Estas afecciones de buen pronóstico y tienen relación clara con el embarazo.
Entre las enfermedades musculares hay que mencionar la miastenia gravis, enfermedad inmunológica que cursa con periodos de debilidad muscular y remisión que empeora durante el embarazo y en ocasiones solo se presenta durante él. Importante mencionar los peligros para el recién nacido atribuibles a la miastenia y a los medicamentos que recibe la madre.

Vamos a dejar de lado en esta revisión lo relacionado con eclampsia y preeclampsia pero comentaremos sobre otras enfermedades de origen cerebrovascular y haremos especial énfasis en la trombosis de senos venosos, entidad que se observa cada día con mayor frecuencia y puede ser mortal. La ayuda de métodos diagnósticos como la resonancia nuclear magnética ha facilitado su diagnóstico para instaurar rápido el tratamiento indicado.

Para terminar, un repaso sobre los movimientos anormales durante el embarazo; la corea gravidarum que solo se presenta durante la gestación, aparece en el primer trimestre y desaparece al pasar la preñez, en los siguientes embarazos puede volver a presentarse, aunque no siempre. Otro movimiento anormal es el temblor postural bien sea de tipo hereditario o inducido por medicamentos simpaticomiméticos. El parkinsonismo y las distonías no son tan comunes.

La idea es revisar y profundizar los temas mencionados antes en una serie de publicaciones llamadas Complicaciones Neurológicas del Embarazo. Comentaremos también algunas entidades que no solo ocurren en embarazadas pero debidas también a cambios hormonales o inducidas por anticonceptivos o trastornos inmunológicos, como son algunos tipos de epilepsia (crisis catameniales) o algunas cefaleas en especial la migraña. 